\title{
BMJ Open The ART of conversation: feasibility and acceptability of a pilot peer intervention to help transition complex HIV-positive people from hospital to community
}

Andrew David Eaton, ${ }^{\oplus 1,2}$ Soo Chan Carusone, ${ }^{3,4}$ Shelley L Craig, ${ }^{1}$ Erin Telegdi, ${ }^{3}$ John W McCullagh, ${ }^{2}$ David McClure, ${ }^{2}$ Walter Wilson, ${ }^{2}$ Leonardo Zuniga, ${ }^{2}$ Kevin Berney, ${ }^{2}$ Galo F Ginocchio, ${ }^{2}$ Gordon A Wells, ${ }^{2}$ Michael Montess, ${ }^{2}$ Adam Busch, ${ }^{2}$ Nick Boyce, ${ }^{5}$ Carol Strike,${ }^{6}$ Ann Stewart ${ }^{7}$

To cite: Eaton AD, Chan Carusone S, Craig SL, et al. The ART of conversation: feasibility and acceptability of a pilot peer intervention to help transition complex HIVpositive people from hospital to community. BMJ Open 2019;9:e026674. doi:10.1136/ bmjopen-2018-026674

\section{- Prepublication history and} additional material for this paper are available online. To view these files, please visit the journal online (http://dx.doi. org/10.1136/bmjopen-2018026674).

Received 17 September 2018 Revised 6 February 2019 Accepted 6 March 2019
Check for updates

(C) Author(s) (or their employer(s)) 2019. Re-use permitted under CC BY-NC. No commercial re-use. See rights and permissions. Published by BMJ.

For numbered affiliations see end of article.

Correspondence to

Andrew David Eaton; andrew.eaton@utoronto.ca

\section{ABSTRACT}

Objectives To pilot a peer-based intervention for people living with HIV who used substances, had challenges with antiretroviral adherence and would be discharged from hospital to community.

Study design A community-based, quasi-experimental pilot intervention study designed to assess feasibility, acceptability and connection to a community-based HIV organisation.

Setting This study was conducted in Toronto, Canada, at Casey House (CH; hospital for people living with HIV) in collaboration with the AIDS Committee of Toronto (ACT; community-based HIV organisation).

Participants People living with HIV who were $\mathrm{CH}$ inpatient between 1 April 2017 and 31 March 2018, struggled with antiretroviral adherence, actively used substances and would be discharged to community were eligible. Forty people met criteria, 19 were approached by an inpatient nurse and 17 consented. Average age was 48.8 years $(S D=11.4), 58.8 \%$ were male and participants averaged 7.8 physical and mental health comorbidities $(\mathrm{SD}=3.1)$.

Intervention Titled 'The ART of Conversation', the threepronged personalised intervention was developed through input from $\mathrm{CH}$ clients and ACT volunteers, all living with HIV. Intervention components were (a) predischarge goalsetting (adherence, substance use and self-identified goal) with the study nurse; (b) predischarge meeting with an HIV+ peer volunteer (PV) and (c) nine postdischarge phone calls between PV and participant, once per day for 3 days, then once per week for 6 weeks.

Primary outcomes Feasibility was measured through proportion of eligible participants recruited and PV availability. Acceptability was assessed through participant interviews at three times (preintervention, postintervention and 6 weeks follow-up) and through PV call logs. Client records determined connection to ACT within the study timeframe.

Results Twelve participants completed the intervention and nine connected with ACT. Predischarge goal-setting and PV meeting were both feasible and acceptable.

\section{Strengths and limitations of this study}

- Patient and public involvement was prioritised throughout this study as people living with HIV co-designed the study and intervention, delivered the intervention and collected and analysed data.

- Peer support models have been identified as a priority area by policymakers to improve care transitions for people living with HIV.

- Interventions for a study population with severe medical and psychosocial complexity who are at high risk of poor health outcomes need to be tested for feasibility and acceptability before launching a larger scale study.

- The key limitations are as follows: the lack of a control group and randomization, which were not possible within our recruitment timeline and sampling frame; a potentially biased sample, as not all eligible participants were approached and incomplete participation, as half of participants missed at least one postdischarge phone call.

Postdischarge phone calls were a challenge as half of completers missed at least one call.

Conclusions Although predischarge goal-setting and PV meeting were feasible, methods to maintain connection following discharge require further investigation.

\section{INTRODUCTION}

Hospital discharge can result in discontinuity of care, non-adherence to medications and other negative outcomes, ${ }^{1}$ especially for people living with $\mathrm{HIV}^{2}{ }^{3}$ who face complex medical and psychosocial challenges. ${ }^{4}$ Medical and psychosocial complexity is multiple, overlapping issues that affect a person's health. ${ }^{5}$ People living with HIV may experience complex medical issues (eg, 
frequent hospitalizations, poor medication adherence, polypharmacy and concurrent comorbidities) ${ }^{67}$ Psychosocial factors may overlap with health challenges (eg, increased substance use, homelessness, unemployment, social isolation and food insecurity). ${ }^{8-10}$ These complex difficulties can interrupt the cascade of care and increase the risk of mortality ${ }^{1}$; in particular, substance use is a priority area of focus for care retention interventions. ${ }^{11}$

The cascade of care (ie, HIV treatment cascade or the HIV care continuum) is a framework recommended by UNAIDS for member countries to measure their progress in ending the AIDS epidemic. ${ }^{2}$ Individual countries, and individual states and provinces within those countries, have adapted this continuum to fit their local contexts $^{12} 13$ and consulted patients in its local implementation. ${ }^{14}{ }^{15}$ However, a common end point is universal among these frameworks: retention in care (ie, attending regular medical appointments and accessing community supports) and maintaining viral suppression $(<50$ copies of HIV per millilitre of blood, meaning that people living with HIV cannot sexually transmit the virus). ${ }^{16}{ }^{17}$ Complex clients living with HIV are often hospitalised to readhere to medications and progress on the care cascade; however, the discharge transition can cause cascade regression and poor health outcomes. ${ }^{18}$ 'Peer' interventions, provided by trained community members who share lived experience with clients, may be a helpful and cost-effective complement to outpatient clinical care in order to help people living with HIV maintain the health progress that they achieved in hospital. ${ }^{19} 20$

Meaningful involvement of people living with HIV as peers has been central throughout the history of HIV and AIDS. ${ }^{2021}$ From the first cases of AIDS to the present day, people living with and affected by HIV have been forming community-based agencies and implementing peer-based models of care. ${ }^{21} 22$ Yet, peer models are understudied among people living with both HIV and complex issues; most work focuses on prevention in the HIV-negative population $^{2123-25}$ or a single issue (most commonly, medication adherence) in the HIV-positive population. ${ }^{19} 20$ Peer interventions that address the more complex realities that some people living with HIV experience are recommended in policy, especially ones that improve linkages between clinical and community-based care. ${ }^{2627}$

To design a peer intervention that could help people living with both HIV and complex issues in the transition from hospital to community, we used the theories of Community-Based Participatory Research (CBPR) and Minimally Disruptive Medicine (MDM). CBPR recommends the equitable involvement of the client population in the design and conduct of a study, ${ }^{28}$ which aligns with this study's aim to pilot a peer intervention. MDM suggests that new interventions may have better results when designed to fit within the context of people's lives. ${ }^{29}$ In this study, CBPR was utilised through extensive consultation and involvement of people living with HIV where the recommendation for the study's intervention-goal setting, peer meeting and postdischarge phone calls—was designed to be minimally disruptive and well acceptable to participants.

With the context of the study's setting at Casey House $(\mathrm{CH})$, a 14-bed HIV hospital with an average 45 days inpatient admission, and funding (1 year CBPR grant), a quasi-experimental pilot was developed to test peer intervention components for feasibility and acceptability.

\section{Objectives}

This study had two objectives. First, to pilot test a peerbased intervention for people living with HIV who had challenges with antiretroviral adherence and substance use and would be discharged from hospital to community; this study of feasibility and acceptability was conducted to determine whether intervention components could be applied in a larger trial. Second, to connect participants to the AIDS Committee of Toronto (ACT) -Canada's largest community-based HIV organisation-for further postdischarge support. As this is a peer intervention, patient and public involvement (PPI) was prioritised so that people living with HIV had an active role in the study's design and conduct.

\section{Study settings}

This study was conducted as a partnership between $\mathrm{CH}$ and ACT in downtown Toronto, Canada. CH is Canada's only standalone hospital for people living with HIV. CH has 14 inpatient beds for subacute, palliative and respite care. Inpatient admissions average approximately 45 days due to mortality risk among most patients. $\mathrm{CH}$ also offers community programmes, and during the operation of this study launched a day health programme to better support adults living with HIV and complex health and psychosocial conditions. ACT is Canada's largest community-based HIV/AIDS organisation and offers prevention (ie, safer sex outreach) and support (ie, counselling, groups) for people living with and affected by HIV. CH was responsible for chart abstraction, goal setting and hosting the peer meeting. ACT was responsible for enrolling participants, training and supervision of PVs and coordinating connection to community-based care.

\section{METHODS}

This study used descriptive quantitative data and qualitative methods to evaluate feasibility and acceptability, and linkage to community supports of a pilot peer intervention that involved people living with HIV in the study's design and conduct.

\section{Study design}

Participants were enrolled into a personalised threestage peer-based intervention. Approximately 40 people were included in the sampling frame (see the Participant flow section). Neither randomisation nor a control group was feasible due to the limited sampling frame and 1 year timeline. 


\section{Patient and public involvement}

People living with HIV became involved in this study as the concept was being developed and were engaged in four distinct activities. First, a community-based exploratory study interviewed $\mathrm{CH}$ clients about the discharge transition and found that participants were requesting peer support. ${ }^{18}$ Second, two $\mathrm{CH}$ client engagement sessions ( $\mathrm{n}=17$, all HIV-positive) were held regarding the structure of a postdischarge peer programme, including, duration, content, definition of 'peer', how peers should be trained and how the pilot should be evaluated. $\mathrm{CH}$ clients living with HIV identified that postdischarge phone support could be easier to access than an in-person peer meeting. Third, a group consultation was held with ACT volunteers $(\mathrm{n}=10)$ who live with HIV and who provide direct service (eg, support groups). This consultation discussed the peer programme requested by $\mathrm{CH}$ clients, programme structure, evaluation methods including draft questionnaires and whether attendees would engage with the study as a peer volunteer (PV) (delivering the intervention) or peer researcher (interviewing participants and analysing data). Fourth, one more $\mathrm{CH}$ client session $(\mathrm{n}=6)$ was facilitated by a peer researcher to continue developing the study questionnaires and intervention details. Based on these consultations, we defined 'peer' as a person living with HIV who has personal or relational experience with substance use. There were two distinct groups of peers in this research team: (a) peer researchers and (b) PVs.

Five peer researchers attended a 1.5-day, 11.5-hours training; the curriculum has been published elsewhere. ${ }^{30}$ The main training component was filmed simulation, where peer researchers were video-recorded conducting simulated interviews to observe their verbal and non-verbal interactions. ${ }^{31}$ Peer researchers refined the study questionnaires, collected all data and participated in the analysis.

Five PVs from ACT delivered this intervention. These volunteers completed a total of 44 training hours. The first 22 hours were dedicated to ACT's core skills volunteer training which covers creating safe and accessible spaces, HIV and health promotion basics, concepts in communication and anti-oppression and cultural competence. The volunteers then attended 22 hours of training specific to the intervention which focused on harm reduction, structuring a phone call, communication tools and self-care.

\section{Participants}

An inpatient nurse at $\mathrm{CH}$ identified people living with HIV who met inclusion criteria (based on admission details) and approached them regarding their interest in learning more about the three-stage peer programme. If people were interested, the principal investigator then met them for enrolment.

\section{Eligibility criteria \\ Inclusion criteria}

People who were HIV-positive; actively used illicit substances (eg, cocaine and crystal meth); inpatient at $\mathrm{CH}$ between
1 April 2017 and 31 March 2018; initiated/restarted antiretroviral therapy while they were inpatient at $\mathrm{CH}$; were discharged back to the community; English-speaking; could access a phone; and provided informed consent.

\section{Exclusion criteria}

People who were at risk of mortality.

\section{Participant identification and consent}

A study nurse (fourth author) identified participants based on their admission presentation (ie, identified substance use and ART initiation/re-initiation). The nurse approached participants to introduce the study and, if they were interested in learning more, then referred them to the principal investigator (first author) for consent. To participate in the study, participants consented to the research and to becoming ACT clients. The consent process also involved discussion with participants of preferences regarding PV matches (eg, schedule).

\section{Intervention}

The intervention consisted of three distinct stages. Participants set discharge goals with the recruiting nurse, then met with a PV prior to discharge. Following discharge, participants scheduled nine phone calls with their PVs over 7 weeks.

\section{Goal-setting}

The study nurse met with participants during their inpatient admission to help them identify three goals that they wanted to achieve after discharge. A nurse was chosen to complete this activity as a means of bridging the clinical care that participants had received in hospital, with the peer support that they would be receiving after discharge. The nurse was trained in motivational interviewing (ie, client-centred counselling to elicit positive goal-setting) ${ }^{32}$ and harm reduction principles (ie, stating that participants could set substance use goals concerning reduced or safer use, not solely abstinence). One goal was related to their ART adherence, another related to their substance use and a third personal goal. These goals were written on a Community Transition Planning (CTP) form (see online supplementary file) that was designed based on principles of motivational interviewing, whereby the facilitators and barriers to a goal are thoroughly discussed. ${ }^{32}$ Participants identified the change they wanted to make, the steps necessary to make this change, support people (both personal and professional supports), their importance and confidence at making the change, and significant events that would occur following discharge. Goal-setting occurred 1week prior to discharge, and typically lasted half an hour. The forms were shared with PVs prior to their meetings with participants.

\section{Peer volunteer meeting}

The principal investigator matched a PV with a participant, based on participant requests (eg, similar substance use history, length of time living with HIV and gender). The dyad met at CH to discuss the participant's CTP form, 


\begin{tabular}{|c|c|c|}
\hline Outcomes & Measures & Description \\
\hline \multirow[t]{2}{*}{ Feasibility } & Participant recruitment and retention & $\begin{array}{l}\text { Proportion of eligible participants who were recruited, } \\
\text { consented and completed the study }\end{array}$ \\
\hline & PV availability & Ability to match PVs with participants \\
\hline \multirow[t]{2}{*}{ Acceptability } & $\begin{array}{l}\text { Semistructured interviews at three times, } \\
\text { conducted by peer researchers }\end{array}$ & $\begin{array}{l}\text { Interview 1: Following PV meeting, prior to discharge } \\
\text { Interview 2: Programme conclusion ( } 7 \text { weeks after discharge) } \\
\text { Interview 3: Follow-up (13 weeks after discharge) }\end{array}$ \\
\hline & Contact logs & Reports from PVs following each phone call \\
\hline $\begin{array}{l}\text { Connection to } \\
\text { ACT (ie, linkage to } \\
\text { community supports) }\end{array}$ & Client records & $\begin{array}{l}\text { Participants accessing an ACT service (eg, counselling and } \\
\text { groups) within } 13 \text { weeks after discharge }\end{array}$ \\
\hline
\end{tabular}

ACT, AIDS Committee of Toronto; PV, peer volunteer.

how the participant was feeling about leaving hospital and the details of phone support (eg, when to call and what to talk about). Discharge goals were further refined in this meeting. PVs were encouraged to self-identify shared experiences that might be relevant (eg, substance use). This meeting occurred in the week leading up to discharge and usually took $45 \mathrm{~min}$.

\section{Postdischarge phone calls}

The PV phoned the participant once per day for the 3 days following discharge, then once per week for the following 6 weeks. This schedule was determined through client consultation; people living with HIV stated that the first 72 hours following discharge were the most difficult and when their risk of relapse was highest. Calls commonly lasted 20-45 min and focused on discharge goals and other issues arising for participants, with a focus on connection to community-based services.

\section{Outcomes}

The outcomes and measures are detailed in table 1 . Feasibility was measured through (a) the proportion of eligible participants who were recruited, consented and completed the study and (b) PV availability. Acceptability was assessed through participant interviews at three times (predischarge, postintervention and 6weeks follow-up) and through logs written by PVs following each phone call. Connection to ACT (ie, linkage to community supports) was determined through a search of client records to see if participants accessed any ACT service (such as counselling or support groups) within 13 weeks after discharge.

\section{Measures}

The intervention components were assessed qualitatively, with participants scheduled to complete three in-depth, semistructured interviews with peer researchers (also living with HIV). The first interview occurred at $\mathrm{CH}$ following the PV meeting but prior to discharge, with questions on goal-setting and peer meeting components, medication adherence, substance use, community supports and overall health. The second interview occurred at ACT at conclusion of peer support (week
7 following discharge). Questions from the first interview were repeated alongside probes for feedback on the postdischarge phone calls and the helpfulness of PVs sharing their own experiences. The third interview was held at ACT 6 weeks after the end of the programme (week 13 following discharge) and, alongside repeated questions from the first and second interviews, focused on supports that the participant had accessed due to the peer programme. Interviews were audio-recorded and averaged 00:41:20 in length.

PVs completed a contact log of each call, noting the call's content and rating how they felt the participant was doing individually (ie, personal well-being), interpersonally (ie, family and close relationships), socially (ie, activity engagement and friendships) and overall (ie, general sense of well-being). These ratings were completed using the Outcome Rating Visual Analog Scale, ${ }^{33}$ where PVs placed a mark on a $10 \mathrm{~cm}$ unnumbered line; instructions stated that marks to the left represented 'not well at all' and marks to the right indicated 'excellent'. PVs were trained to conduct these assessments through instruction on rating participants against how they presented in the initial PV meeting. For example, a PV would assess the interpersonal domain based on a participant's progress on reconnecting with their daughter, if the participant identified this goal in the initial meeting.

\section{Sample size}

A sample size of 15 was selected for feasibility as (a) $\mathrm{CH}$ has an average 80 discrete admissions annually; (b) a clinical estimate based on retrospective chart review found that approximately half of admissions met this study's criteria; (c) the hospital moved locations during our recruitment year, disrupting recruitment for approximately 1 month and (d) based on existing pilot studies, this sample size would allow the team to assess the feasibility and acceptability of intervention components across diverse experiences. $^{34} 35$ 


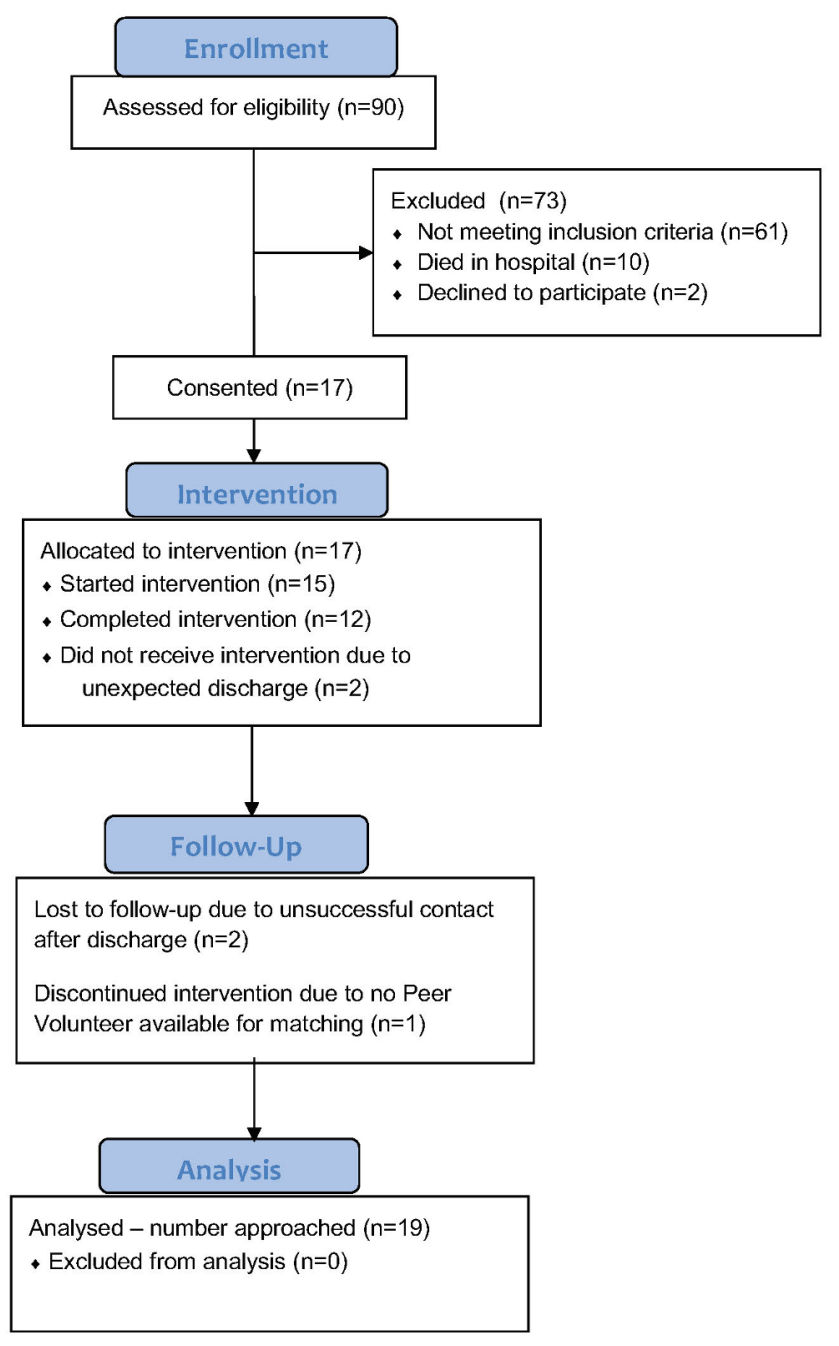

Figure 1 Participant flowchart.

\section{Data analysis}

Research assistants (authors 10-12) transcribed interviews and entered data. The entire team held three iterative analysis meetings (4hours each) to read through the data and apply content analysis. Content analysis, as used in other qualitative assessments of intervention research ${ }^{36}$ included discussion on how findings corresponded to the study's objectives, and which quotes illuminated the facilitators and barriers of each intervention component. ${ }^{37}$ Contact log data are presented as a spaghetti plot; while the sample size limits our ability to interpret these findings, they provide context for the quotes.

\section{RESULTS}

The participant flow and characteristics are presented, followed by numbers analysed and outcomes concerning the feasibility and acceptability of intervention components. Participant quotes include a unique identifier and gender.

\section{Participant flow}

Figure 1 shows the flow of participants throughout the study. Of the 90 discrete inpatient admissions at $\mathrm{CH}$ during the recruitment period, 73 were excluded due to (a) an eligibility review of admission presentation, namely mortality risk $(\mathrm{n}=21)$ and unidentified substance use $(\mathrm{n}=40)$; (b) death in hospital $(\mathrm{n}=10)$ and (c) declining to participate $(n=2)$. Mortality risk was determined by an admission for palliative care or when the clinical team determined that a person was too medically unstable to participate. Unidentified substance use means that neither inpatients themselves nor their referring clinician identified substance use at admission.

\section{Recruitment}

A CH nurse approached people who (a) were inpatient at $\mathrm{CH}$ during the period of 1 April 2017 to 31 March 312018 and (b) self-identified substance use and challenges with antiretroviral adherence. Nineteen people were approached and two declined, leaving 17 consenting to participate. Follow-up occurred 7 weeks following discharge (second interview) and 13 weeks following discharge (interview three), with the final interview occurring on 11 July 2018. The pilot programme ended at this time due to the 1 year funding agreement.

\section{Baseline data}

Participants were predominately male $(58.8 \%, \mathrm{n}=10)$ and had an average age of 48.8 ( $\mathrm{SD}=11.4)$ years. Comorbidities $(\mathrm{M}=7.8, \mathrm{SD}=3.1)$ most commonly were cancer, hepatitis $\mathrm{C}$ and COPD; participants also had mental health diagnoses $(\mathrm{M}=3.2, \mathrm{SD}=1.5)$, most commonly mood disorders (eg, bipolar disorder and depressive disorders) and organic mental disorders (eg, HIV-associated neurocognitive disorder). Substances identified were mostly cocaine (47.1\%, n=8), opioids (29.4\%, $\mathrm{n}=5$ ) and crystal meth $(29.4 \%, \mathrm{n}=5)$. Participants were in hospital for an average of 44.3 days $(\mathrm{SD}=42.4)$ and were taking an average of 11.8 $(\mathrm{SD}=6.2)$ medications at discharge. Refer to table 2 for further participant characteristics.

\section{Numbers analysed}

For feasibility, results are presented against a denominator of 19 (number of participants approached); this includes 2 people who declined to participate and 5 who did not complete the intervention. For acceptability, a denominator of 12 is used as this number of people participated in all intervention components and completed follow-up interviews.

\section{OUTCOMES}

The intervention was feasible to recruit and coordinate, and led to participant connection to ACT services. The first two intervention components (goal-setting and PV meeting) were highly acceptable to participants, while the third (post-discharge phone calls) was well received by half of completers but the other half had challenges 


\begin{tabular}{|c|c|}
\hline Characteristic & N (\%)/Mean (SD) \\
\hline \multicolumn{2}{|l|}{ Gender } \\
\hline Male & $10(58.8)$ \\
\hline Female & $7(41.2)$ \\
\hline Age (years) & $48.8(S D=11.4)$ \\
\hline \multicolumn{2}{|l|}{ Income source } \\
\hline $\begin{array}{l}\text { Ontario Disability Support } \\
\text { Program (ODSP) }\end{array}$ & $11(64.7)$ \\
\hline Other & $6(35.3)$ \\
\hline \multicolumn{2}{|l|}{ Employment status } \\
\hline On disability & $11(64.7)$ \\
\hline Unemployed & $6(35.3)$ \\
\hline \multicolumn{2}{|l|}{ Comorbidities } \\
\hline Mental health diagnoses & $3.2(\mathrm{SD}=1.5)$ \\
\hline Total comorbidities & $7.8(S D=3.1)$ \\
\hline \multicolumn{2}{|l|}{ Housing prior to admission } \\
\hline Independent living & $9(52.9)$ \\
\hline Supportive housing & $5(29.4)$ \\
\hline Shelter & $1(5.9)$ \\
\hline Street-involved & $1(5.9)$ \\
\hline Rooming house & $1(5.9)$ \\
\hline \multicolumn{2}{|l|}{ Housing following discharge } \\
\hline Independent living & $9(52.9)$ \\
\hline Supportive housing & $6(35.3)$ \\
\hline Rooming house & $1(5.9)$ \\
\hline Unknown & $1(5.9)$ \\
\hline \multicolumn{2}{|l|}{ Reason for admission } \\
\hline ART re-/initiation & $7(41.2)$ \\
\hline Psychosocial issues & $5(29.4)$ \\
\hline Acute medical condition & $2(11.8)$ \\
\hline Respite & $2(11.8)$ \\
\hline Postsurgical recovery & $1(5.9)$ \\
\hline Years living with HIV & $16.2(\mathrm{SD}=9.1)$ \\
\hline \multicolumn{2}{|l|}{ CD4 (n=14) } \\
\hline$>500$ & $5(35.7)$ \\
\hline $200-500$ & $4(28.6)$ \\
\hline$<200$ & $5(35.7)$ \\
\hline
\end{tabular}

Substances identified (most common)

\begin{tabular}{ll} 
Crack cocaine & $8(47.1)$ \\
\hline Opioids & $5(29.4)$ \\
Crystal meth & $5(29.4)$ \\
$\begin{array}{l}\text { Total number of medications at } \\
\text { discharge }\end{array}$ & $11.8(\mathrm{SD}=6.2)$ \\
$\begin{array}{l}\text { Postdischarge care } \\
\text { Family doctor }\end{array}$ & $17(100)$ \\
\hline
\end{tabular}

Continued

\begin{tabular}{ll}
\hline Table 2 Continued & \\
\hline Characteristic & N (\%)/Mean (SD) \\
\hline \multicolumn{1}{c}{$\begin{array}{l}\text { Allied health (nursing, } \\
\text { psychiatry and social work) }\end{array}$} & $17(100)$ \\
Substance use programme & $9(52.9)$ \\
HIV specialist & $7(41.2)$ \\
Adherence reminders & $5(29.4)$ \\
Length of admission & 44.3 days (SD $=42.4)$, \\
& Median=26 \\
\hline
\end{tabular}

engaging by phone. PPI contributed positively to study outcomes. Throughout the interviews, participants stated how much they appreciated that people living with HIV collaborated in the study's design, delivered the intervention and conducted their interviews.

\section{Feasibility}

Overall, $63.1 \% \quad(\mathrm{n}=12)$ of participants who were approached completed the intervention. Within a 1 year recruitment timeline, 5 PVs were matched with 16 participants (ie, each volunteer had approximately three matches); there was only one instance where no volunteer was available to be matched with a participant. PPI may have contributed to ease of recruitment, as potential participants had heard about the study and contributed to its design. PVs received modest compensation at $\$ 150$ per match.

\section{Acceptability}

The goal-setting and peer meeting components were acceptable to participants, with strong participation and positive feedback in interviews. Post-discharge phone calls were a challenge, as half of the participants who participated in this component $(\mathrm{n}=6)$ lost their phones, changed their numbers and/or did not answer at some point over the 6 weeks of the programme. This left six participants completing all nine calls as scheduled. From the 12 participants who engaged with phone calls, the mean number of calls per match was 5.8. Acceptability results for each intervention component are detailed below.

\section{Goal-setting acceptability}

Most participants $(\mathrm{n}=15)$ identified goals for the 7 weeks after discharge related to (1) antiretroviral adherence, (2) substance use and (3) a personal goal (most commonly, housing and social connection). Participants rated their importance and confidence of each goal on a scale from ' 1 ' (not at all) to ' 10 ' (very much); figure 2 shows these results.

Participants expressed a high degree of confidence in achieving their adherence goals, despite a reported history of challenges. Substance use goals were primarily abstinence based and had the lowest confidence of success. Open-ended goals were identified as the most important and primarily focused on improving living 
Open - participant identified (e.g., housing, social connection)

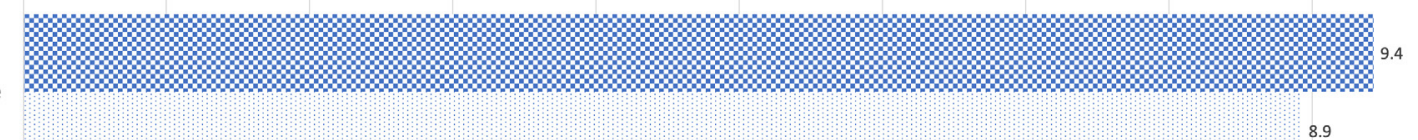

Substance use

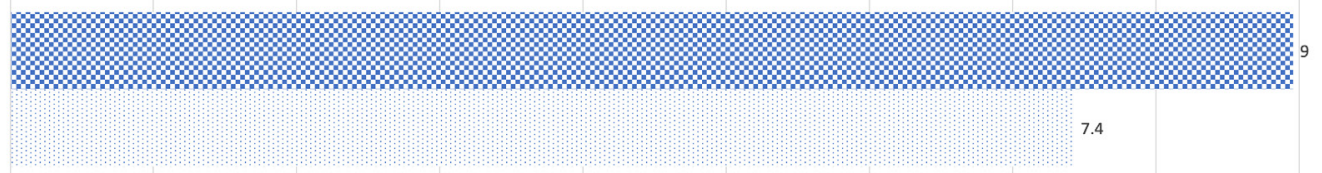

Figure 2 Participant goals: self-rated importance and confidence.

space and social connections. One participant described the goal-setting process as follows:

[The nurse and I] went over my needs and my goals. Where my frame of mind was at. What things did I think would help me turn this rig around, kinda? [The nurse] figured who I could see to help me along the way...she was top shelf, y'know?... Like hey, yeah, she let me talk and she let me kind of lead the way and then she wrote down [my goals]. It [took] about twenty minutes, and then again after she wrote everything down and she filled out her form, then came back and showed me...to verify she had captured everything (P15, male).

Another participant talked about how familiarity with the nurse helped the goal-setting process:

Me and [nurse] have always gotten along great. Well, I get along with all the nurses but there's a couple that I can talk to about anything and she's one of them...it made me think, let's try this [program]. Give it a fair shot (P16, female).

\section{Peer volunteer meeting acceptability}

Thirteen participants met with an ACT PV at CH, following goal-setting and prior to discharge, to discuss upcoming discharge, goals and to make a plan for post-discharge phone calls. Participants appreciated the opportunity to meet with a peer; this was their first non-clinical service interaction during their hospital stay. As one person said, 'He told me where he's at...and
I shared a bit, [I was] thinking this guy is going to be a counsellor... and then I realized, huh, this guy's on my level' (P3, male).

In the consultations with people living with HIV to design this study, the issue of demographics was raised regarding whether people would be able to connect across ages, genders, etc. Participants felt comfortable connecting with their volunteer regardless of these identities, with one participant saying

I wasn't expecting somebody that young to be able to interact with me and understand me...I was even more comfortable when she told me she had HIV. And then I forgot all about [demographics], like we started talking you know she knows how to interact. It's not a thing anybody can do. It's not just about asking the questions it's about making the person feel comfortable and she did that with me (P6, female).

\section{Postdischarge phone call acceptability}

PVs phoned participants once per day for the first 3 days following discharge, then once per week for the following 6 weeks. The phone calls were the most challenging component of this intervention as half of the participants lost their phones, changed their numbers and/or did not answer at some point over the programme's duration. Participants engaged well while on the phone, speaking with PVs about their discharge goals, other issues in their lives and how to improve their health and social engagement. 
Some participants appreciated the flexibility of phone calls and felt they could engage with a PV in this manner, as one person said

The way we were able to interact, communicate, understand. It was like he understood everything I was saying and I understood everything he was saying. And it was great. I couldn't imagine not having someone like him. Yes, because it made me think, how do I explain it, in the last few years, I've been stuck in a hole. Like it just flew, no one to talk to, not one to help, nowhere to reach out, no nothing. When [Volunteer] came along it was like having a peer in a different type of background and culture (P9, male).

Phone calls occasionally occurred at important times for participants, as shown in the following quote:

A lot of the time I couldn't get in touch with my [in-person outpatient supports] but my peer would call me every week, she was a big help. I almost had a few relapses, but I didn't [relapse]. Actually it was my peer, once I was about to use and she called me! It was so weird, but in a good way. I told her I really need this call right now (P13, female).
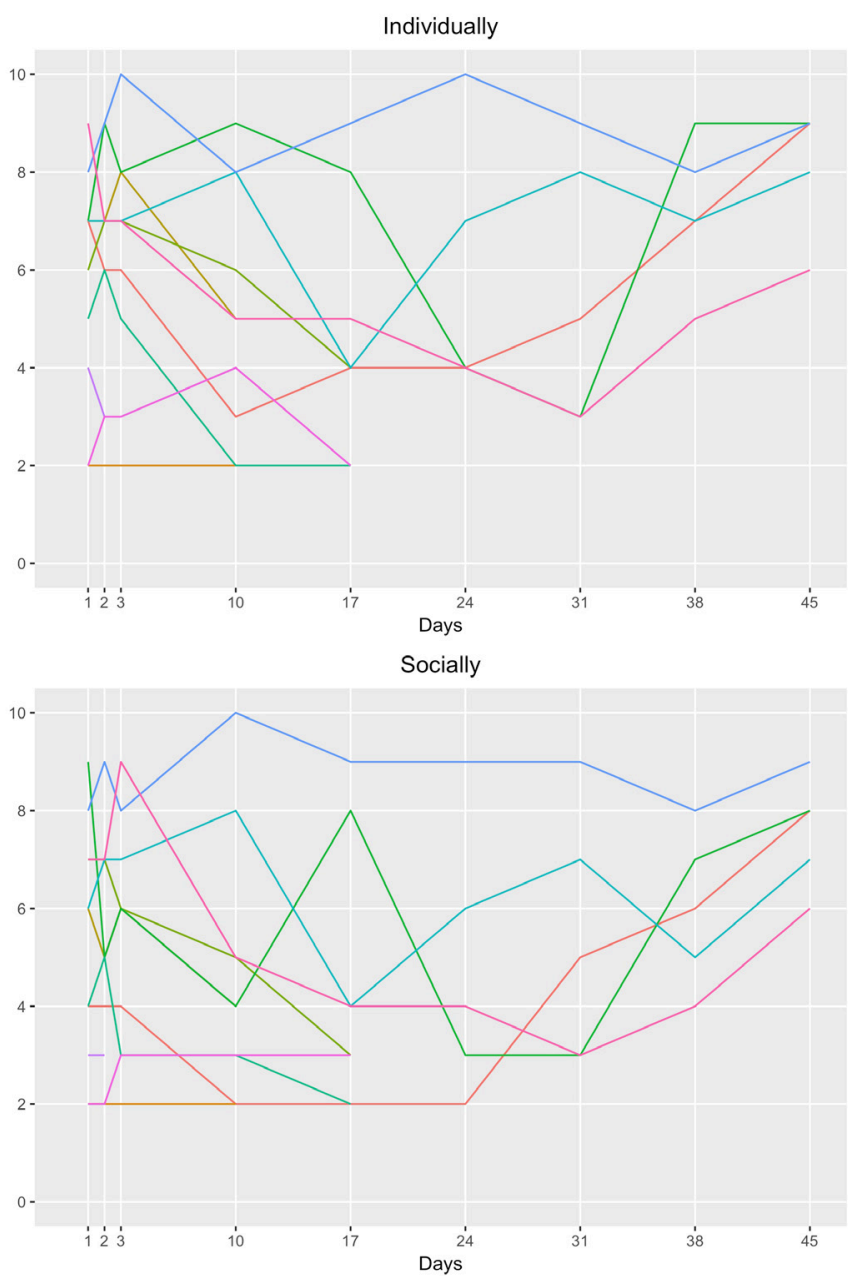

Other participants indicated that the phone calls felt impersonal and that in-person peer support was preferable, with a participant saying 'I'm just not a phone person...I don't know, I just can't. It's easier [in-person], you don't really know somebody [over the phone]' (P1, female).

Figure 3 displays the Visual Analog Scale results from the PV call logs. Overall, the most difficult period was 1-2 weeks postdischarge with participants improving by $5-6$ weeks after leaving hospital. Participants who were lost to follow-up were rated lower than people who completed the programme.

\section{Connection to ACT}

Over half $(57.9 \%, \mathrm{n}=11)$ of the total sample connected to ACT services. Interestingly, two participants who did not complete the intervention (one was lost to follow-up and we were unable to match the other with a PV) still connected to ACT. ACT services that participants accessed included counselling, support groups and lunch programmes.

\section{Harms}

There were no reported study-related harms.

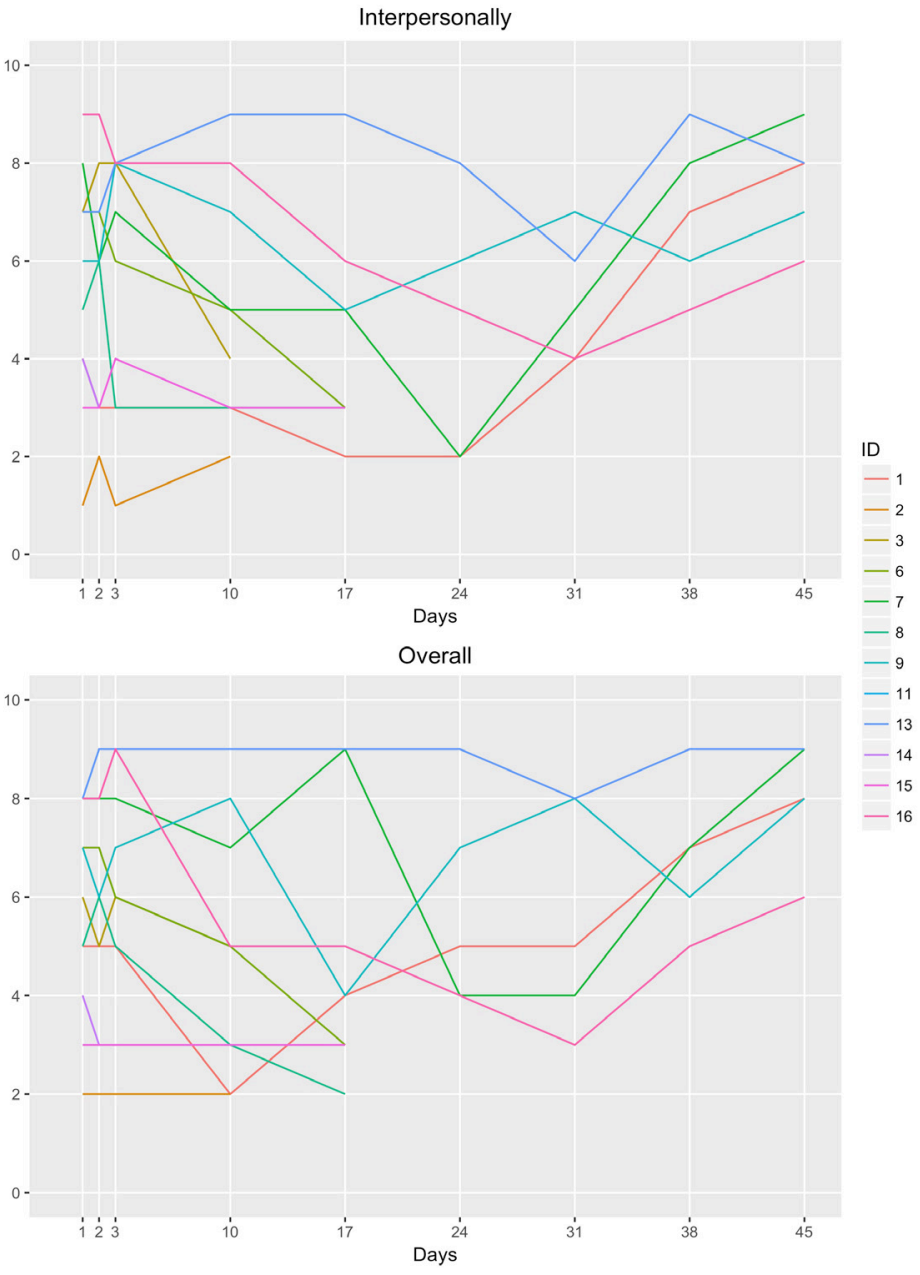

Figure 3 Peer volunteer assessment of participants following each call. 


\section{DISCUSSION}

The principal findings of this pilot are as follows: (a) predischarge goal-setting and a PV meeting were feasible and acceptable for a sample of people living with HIV and complex needs; (b) while some participants appreciated postdischarge phone calls, others experienced barriers to this method of engagement and (c) a clinical and community-based HIV organisation can partner for improved connection to care.

Compared with other studies, a strength of this study was its substantial involvement of people living with HIV at multiple stages. This PPI approach may have made recruitment easier and contributed towards the positive experience that participants had with multiple intervention components. ${ }^{38}$ Another strength was this study's focus on people with complex needs; participants averaged eight comorbidities (eg, AIDS, cancer and hepatitis C) and are commonly lost to follow-up from outpatient clinical care at $\mathrm{CH}$, so the finding that $65 \% \quad(\mathrm{n}=11)$ connected with ACT services suggests that peer support can be a helpful catalyst in the discharge transition. ${ }^{20}$

For clinicians, this study presents two intervention components-predischarge goal setting and peer meeting - that can be feasibly incorporated into practice at low cost and time commitment, which may ease the discharge transition for people experiencing complex medical and psychosocial needs. For policymakers, this study responds to a call for greater collaboration between clinical and community-based care ${ }^{26}$ by highlighting how a hospital and a community agency can partner to provide peer support.

The goal-setting and peer meeting intervention components need to be tested in a larger trial with greater rigour and a sufficient sample, using standardised measures, to properly ascertain their effectiveness. A larger study should consider results from other peer support trials, such as a null effect on antiretroviral adherence due to low-intensity (ie, phone support) interventions ${ }^{39}$ and significant results in adherence and care retention through home visits. ${ }^{40}$ Future research on postdischarge peer support with a complex population group should therefore explore more intensive supports than weekly phone contact; in-person follow-up, whether meeting in social spaces (such as coffee shops), home visits or outpatients returning to hospital for postdischarge peer groups could be combined with phone calls as more supportive methods of retaining people in care.

\section{Limitations}

This study has several limitations. Without randomization and control and with a small sample, there remains uncertainty regarding the two promising intervention components (goal-setting and peer meeting). Other peer support studies have found significant effects in larger samples by focusing on a single issue of concern. ${ }^{19}{ }^{20} \mathrm{~A}$ PPI limitation was the mixed results from the postdischarge phone calls. Phone support had been specifically requested from current and former $\mathrm{CH}$ clients living with
HIV, during our consultations to design this study, as they perceived it to be a convenient and minimally disruptive way of accessing peer support. There is a risk of selection bias as eligible participants who were at risk of mortality were not approached. ${ }^{41} \mathrm{PV}$ assessments of participants may have been biased, likely in the direction of showing positive change. ${ }^{42}$ Incomplete participation among a small sample requires that the results be interpreted with some caution.

\section{Applicability}

The goal-setting and peer meeting components show preliminary promise for easing the discharge transition for people living with HIV and complex needs. These components could be more rigorously tested by other hospitals, where peers can be adequately trained and supported, to address high rates of lost-to-follow-up and eventual readmission for complex clients.

\section{Interpretation}

While there is some uncertainty regarding this study's benefits, we found no evidence of study harm. Peer support has been found effective on single issues regarding HIV (such as medication adherence ${ }^{1920}$; this study's attempt to pilot peer support regarding more complex needs is a first step towards better supporting the more marginalised people living with HIV who require more targeted support than is currently offered. This study's positive results with connection to ACT services aligns with other studies that found improved care engagement as a result of a peer intervention. ${ }^{40} 4344$ Qualitatively, this study's participants expressed views similar to other peer intervention studies regarding the ease of speaking with a peer and the benefit of shared experience. ${ }^{19} 4546$ However, this study found that PVs and participants were able to connect despite differences in age, health status and other demographics, which differs from other studies that recommend peers share as many subgroup characteristics as possible. ${ }^{45} 47$

The PPI approach helped facilitate study recruitment and the first two intervention components, yet the third component (postdischarge phone calls) received mixed results despite its PPI influence. Given this study's results and in-person peer support showing better outcomes than postdischarge phone calls in other quasi-experimental studies, ${ }^{48} 49$ a future postdischarge peer support study could combine phone and in-person meetings. Multiple methods of engagement may be more acceptable to participants and contribute to greater completion rates, which could lead to better outcomes.

\section{CONCLUSION}

This pilot study presents two intervention components (goal-setting and PV meeting) that have preliminary proof-of-concept in easing the discharge transition and connection to community-based care for people living with HIV and complex needs. More research is needed to 
determine the ideal form of postdischarge peer support for this population.

\section{Author affiliations}

${ }^{1}$ University of Toronto, Factor-Inwentash Faculty of Social Work, Toronto, Ontario,

Canada

${ }^{2}$ AIDS Committee of Toronto, Toronto, Ontario, Canada

${ }^{3}$ Casey House, Toronto, Ontario, Canada

${ }^{4}$ Department of Health Research Methods, Evidence, and Impact, McMaster University, Hamilton, Ontario, Canada

${ }^{5}$ Ontario Harm Reduction Network, Toronto, Ontario, Canada

${ }^{6}$ Dalla Lana School of Public Health, University of Toronto, Toronto, Ontario, Canada

${ }^{7}$ St. Michael's Hospital, Toronto, Ontario, Canada

Acknowledgements We wish to thank all our study participants for their voluntary participation, and all of the people living with HIV who contributed to the study's design. Thanks to Dr Sharon Walmsley for critically reviewing this manuscript and to Leah Szadkowski and Minnie Cui for assistance with the figures.

Contributors ADE oversaw all study activities, supervised personnel, consented participants, led the analysis and interpretation of results and wrote the first draft of the manuscript. SCC led patient engagement activities and co-led analysis and interpretation of results. SLC co-led analysis and interpretation of results and met monthly with ADE and SCC to discuss study progress. ET facilitated participant goal-setting and coordinated peer volunteer meetings and discharge timing. JWMC, DMC, WW, LZ and KB contributed to study design and collected data. GFG, GAW and MM prepared data for analysis through transcription and data entry. $A B$ and NB trained peer volunteers with ADE. CS and AS contributed to study design and analysis. All the authors co-conceptualized the study, contributed to analysis, critically reviewed the manuscript and approved the final submitted version of the manuscript.

Funding This work was funded by the Ontario HIV Treatment Network (OHTN) through a Community-Based Research and Evaluation Grant (Grant number CBRG1074), with additional support from Universities Without Walls and the Canadian Association for HIV Research through their Flipped Workshop Mentoring program. ADE is supported by an OHTN Endgame Leader Award. SLC is a Canada Research Chair.

Disclaimer The funders did neither have a role in the design and conduct of the study, nor in the decision to submit the study for publication.

Competing interests None declared.

Patient consent for publication Not required.

Ethics approval This study was approved by the University of Toronto's HIV/AIDS Research Ethics Board (Protocol ID\# 34124).

Provenance and peer review Not commissioned; externally peer reviewed.

Data sharing statement Data not reported in this article (ie, de-identified interview transcripts) may be available, pending consultation with the University of Toronto's HIV/AIDS Research Ethics Board (REB). Data requests may be sent to the principal investigator at andrew.eaton@utoronto.ca, who will consult with the REB.

Open access This is an open access article distributed in accordance with the Creative Commons Attribution Non Commercial (CC BY-NC 4.0) license, which permits others to distribute, remix, adapt, build upon this work non-commercially, and license their derivative works on different terms, provided the original work is properly cited, appropriate credit is given, any changes made indicated, and the use is non-commercial. See: http://creativecommons.org/licenses/by-nc/4.0/.

\section{REFERENCES}

1. Allaudeen N, Vidyarthi A, Maselli J, et al. Redefining readmission risk factors for general medicine patients. J Hosp Med 2011;6:54-60.

2. Kay ES, Batey DS, Mugavero MJ. The HIV treatment cascade and care continuum: updates, goals, and recommendations for the future. AIDS Res Ther 2016;13:1-7.

3. Kimmel AD, Martin EG, Galadima H, et al. Clinical outcomes of HIV care delivery models in the US: a systematic review. AIDS Care 2016;28:1215-22.

4. Schaink AK, Kuluski K, Lyons RF, et al. A scoping review and thematic classification of patient complexity: offering a unifying framework. J Comorb 2012;2:1-9.
5. Grudniewicz A, Nelson M, Kuluski K, et al. Treatment goal setting for complex patients: protocol for a scoping review. BMJ Open 2016;6:e011869.

6. Omland LH, Ahlström MG, Obel N. Cohort profile update: the Danish HIV Cohort Study (DHCS). Int J Epidemiol 2014;43:1769-1769e.

7. Hasse $\mathrm{B}$, Ledergerber $\mathrm{B}$, Furrer $\mathrm{H}$, et al. Morbidity and aging in HIV-infected persons: the Swiss HIV cohort study. Clin Infect Dis 2011;53:1130-9.

8. Bekele T, Globerman J, Watson J, et al. Prevalence and predictors of food insecurity among people living with HIV affiliated with AIDS service organizations in Ontario, Canada. AIDS Care 2018;30:663-71.

9. Halman M, Carusone SC, Stranks S, et al. Complex care needs of patients with late-stage HIV disease: a retrospective study. AIDS Care 2014;26:320-5.

10. Rueda S, Law S, Rourke SB. Psychosocial, mental health, and behavioral issues of aging with HIV. Curr Opin HIV AIDS 2014;9:325-31.

11. Szadkowski L, Walmsley S, Burchell AN, et al. High retention in HIV care at a tertiary care centre in Toronto, Canada. AIDS Care 2018;30:246-54.

12. Edun $\mathrm{B}$, lyer $\mathrm{M}$, Albrecht $\mathrm{H}$, et al. The south carolina hiv cascade of care. South Med J 2015;108:670-4.

13. Powers KA, Miller WC. Critical review: Building on the HIV cascade. JAIDS 2015;69:341-7.

14. Bruton J, Rai T, Day S, et al. Patient perspectives on the HIV continuum of care in London: a qualitative study of people diagnosed between 1986 and 2014. BMJ Open 2018;8:e020208.

15. Rachlis B, Burchell AN, Gardner S, et al. Social determinants of health and retention in HIV care in a clinical cohort in Ontario, Canada. AIDS Care 2017;29:828-37.

16. Cohen MS, Chen YQ, McCauley M, et al. Antiretroviral therapy for the prevention of hiv-1 transmission. $N$ Engl J Med Overseas Ed 2016;375:830-9.

17. Rodger AJ, Cambiano V, Bruun T, et al. Sexual activity without condoms and risk of hiv transmission in serodifferent couples when the hiv-positive partner is using suppressive antiretroviral therapy. JAMA 2016;316:171-81.

18. Carusone SC, O'Leary B, McWatt S, et al. The Lived Experience of the Hospital Discharge "Plan": A Longitudinal Qualitative Study of Complex Patients. J Hosp Med 2017:12:5-10.

19. Genberg BL, Shangani S, Sabatino K, et al. Improving Engagement in the HIV Care Cascade: A Systematic Review of Interventions Involving People Living with HIV/AIDS as Peers. AIDS Behav 2016;20:2452-63.

20. Simoni JM, Nelson KM, Franks JC, et al. Are peer interventions for HIV efficacious? A systematic review. AIDS Behav 2011;15:1589-95.

21. Shangani S, Escudero D, Kirwa K, et al. Effectiveness of peerled interventions to increase HIV testing among men who have sex with men: a systematic review and meta-analysis. AIDS Care 2017;29:1003-13.

22. Eaton AD, Tsang AKT, Craig SL, et al. Peer researchers in postprofessional healthcare: A glimpse at motivations and partial objectivity as opportunities for action researchers. Action Res $J$ 2018.

23. Kerrigan DL, Fonner VA, Stromdahl S, et al. Community empowerment among female sex workers is an effective HIV prevention intervention: a systematic review of the peer-reviewed evidence from low- and middle-income countries. AIDS Behav 2013;17:1926-40.

24. Maticka-Tyndale E, Barnett JP. Peer-led interventions to reduce HIV risk of youth: a review. Eval Program Plann 2010;33:98-112.

25. Medley A, Kennedy C, O'Reilly K, et al. Effectiveness of peer education interventions for HIV prevention in developing countries: a systematic review and meta-analysis. AIDS Educ Prev 2009;21:181-206.

26. Bacon J. the Ontario Advisory Committee on HIV/AIDS. HIV/AIDS strategy to 2026: Focusing our efforts - changing the course of the HIV prevention, engagement and care cascade in Ontario. Ministry of Health and Long Term Care. 2016. http://www.health.gov.on.ca/en/ pro/programs/hivaids/docs/oach_strategy_2026.pdf.

27. UNAIDS. Communities deliver: The critical role of communities in reaching global targets to end the AIDS epidemic. UNAIDS 2015 http://www.unaids.org/sites/default/files/media_asset/UNAIDS_ JC2725 CommunitiesDeliver en.pdf.

28. Israel BA, Coombe CM, Cheezum RR, et al. Community-based participatory research: a capacity-building approach for policy advocacy aimed at eliminating health disparities. Am J Public Health 2010;100:2094-102.

29. May C, Montori VM, Mair FS. We need minimally disruptive medicine. BMJ 2009;339:b2803. 
30. Eaton AD, Ibáñez-Carrasco F, Craig SL, et al. A blended learning curriculum for training peer researchers to conduct communitybased participatory research. Action Learning: Research and Practice 2018;15:139-50.

31. Eaton AD. Filmed simulation to train peer researchers in communitybased participatory research. Soc Work Res. In Press.

32. Hettema J, Steele J, Miller WR. Motivational interviewing. Annu Rev Clin Psychol 2005;1:91-111.

33. Campbell A, Hemsley S. Outcome rating scale and session rating scale in psychological practice: Clinical utility of ultra-brief measures. Clin Psychol 2009;13:1-9.

34. Imes CC, Dougherty CM, Lewis FM, et al. Outcomes of a pilot intervention study for young adults at risk for cardiovascular disease based on their family history. J Cardiovasc Nurs 2016;31:433-40.

35. Pettifor A, MacPhail C, Nguyen N, et al. Feasibility and acceptability of Project Connect: a couples-based HIV-risk reduction intervention among young couples in Johannesburg, South Africa. AIDS Care 2014;26:476-82.

36. Pérez-Jiménez D, Orengo-Aguayo RE. Qualitative analysis of an educational intervention with HIV-discordant heterosexual Latino couples. P R Health Sci J 2011;30:188-94.

37. Bengtsson M. How to plan and perform a qualitative study using content analysis. NursingPlus Open 2016;2:8-14.

38. Eaton AD, Cattaneo JS, Watchorn JM, et al. From serodiscordant to magnetic: The feasibility and acceptability of a pilot psychoeducational group intervention designed to improve relationship quality. Soc Work Groups 2018;41:323-35.

39. Simoni JM, Pantalone DW, Plummer MD, et al. A randomized controlled trial of a peer support intervention targeting antiretroviral medication adherence and depressive symptomatology in HIVpositive men and women. Health Psychol 2007;26:488-95.

40. Chang LW, Nakigozi G, Billioux VG, et al. Effectiveness of peer support on care engagement and preventive care intervention utilization among pre-antiretroviral therapy, HIV-infected adults in Rakai, Uganda: a randomized trial. AIDS Behav 2015;19:1742-51.

41. Henderson M, Page L. Appraising the evidence: what is selection bias?. Evid Based Ment Health 2007;10:67-8.

42. Walfish S, McAlister B, O'Donnell P, et al. An investigation of self-assessment bias in mental health providers. Psychol Rep 2012;110:639-44.

43. Hatcher AM, Turan JM, Leslie HH, et al. Predictors of linkage to care following community-based HIV counseling and testing in rural Kenya. AIDS Behav 2012;16:1295-307.

44. Richter L, Rotheram-Borus MJ, Van Heerden A, et al. Pregnant women living with HIV (WLH) supported at clinics by peer WLH: a cluster randomized controlled trial. AIDS Behav 2014;18:706-15.

45. Hallum-Montes R, Morgan S, Rovito HM, et al. Linking peers, patients, and providers: a qualitative study of a peer integration program for hard-to-reach patients living with HIV/AIDS. AIDS Care 2013;25:968-72.

46. Koester KA, Morewitz M, Pearson C, et al. Patient navigation facilitates medical and social services engagement among HIVinfected individuals leaving jail and returning to the community. AIDS Patient Care STDS 2014;28:82-90.

47. Yan $\mathrm{H}$, Zhang $\mathrm{R}$, Wei $\mathrm{C}$, et al. A peer-led, community-based rapid HIV testing intervention among untested men who have sex with men in China: an operational model for expansion of HIV testing and linkage to care. Sex Transm Infect 2014;90:388-93.

48. Mash R, Mash RJ. A quasi-experimental evaluation of an HIV prevention programme by peer education in the Anglican Church of the Western Cape, South Africa. BMJ Open 2012;2:e000638.

49. Harper GW, Bangi AK, Sanchez B, et al. A quasi-experimental evaluation of a community-based HIV prevention intervention for Mexican American female adolescents: the SHERO's program. AIDS Educ Prev 2009;21:109-23. 